\title{
Accidental displacement of gutta-percha to the lingual periosteum: a case report
}

\author{
Adnan Kılınç, Bahadır Sancar, Nesrin Saruhan, Ümit Ertaş \\ Department of Oral and Maxillofacial Surgery, Ataturk University Faculty of Dentistry, Erzurum, Turkey
}

\begin{abstract}
Debridement and complete obstruction of a root canal system are success criteria of root canal treatment. Endodontic failure is usually due to broken instruments, perforations, overfilling, underfilling, and ledges. Root perforation and the accidental displacement of a gutta-percha point from the periosteum to bone is a rare complication in clinical dental practice. The aim of this report is to present a clinical case of accidental displacement of two gutta-perchas to lingual periosteum in the mandibular premolar region, along with its surgical treatment. After surgical removal of the gutta-perchas, the patient's clinical symptoms were eliminated. Surgery is the most accepted treatment for accidentally displaced gutta-percha.
\end{abstract}

Keywords: Gutta-percha; lingual periosteum; surgical treatment.

$\mathrm{D}$ ebridement and obstruction of the root canal system are the success criteria of root canal treatment. [1] The extraction of all diseased pulp and dentin, sufficient shaping and cleaning of the root canal system, and its three-dimensional obstruction and sealing comprise the primary basis of root canal treatment. ${ }^{[2]}$ Ideally, the filling material should be restricted to the root canal and not extruded to periapical tissues or anatomic structures. ${ }^{[3]}$ Overfilling is one of the complications of root canal treatment in endodontics. The most commonly used root canal filling material is gutta-percha, with or without a sealer. ${ }^{[4]}$ Gutta-percha has a low degree of toxicity when compared with other components used in endodontic obstruction and has withstood the test of time in clinical usage. ${ }^{[5]}$ The purpose of this unusual case report is to present the surgical removal of two displaced gutta-perchas from lingual periosteum in the mandibular premolar region.

\section{Case report}

A 48-year-old man, complaining of continuous pain and discomfort in his right mandibular premolar region since last week, was referred to our department. Clinically, periodontal disease due to bad oral hygiene and caries of the right mandibular first premolar tooth were diagnosed. The patient presented with tenderness and pain to mild touch at the vestibular sulcus in the premolar region. Radiographically, two radiopaque linear body formations were observed, located between the root of the premolar tooth and the border of the mandible (Figure la). Root canal treatment had been applied to the lower right second premolar more than three years earlier, and then it was extracted three months ago. We thought that the gutta-perchas were resulted from endodontic treatment of the second premolar tooth. Because endodontic treat-

Correspondence: Dr. Nesrin Saruhan. Atatürk Üniversitesi Diş Hekimliği Fakültesi,

Ağız Diş ve Çene Cerrahisi Anabilim Dalı, Erzurum, Turkey.

Tel: +90 442 - 2311801 e-mail: dt_nesrin@yahoo.com

Submitted: February 09, 2016 Accepted: April 05, 2016

(c)2016 Turkish Endodontic Society

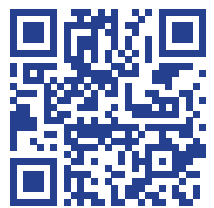



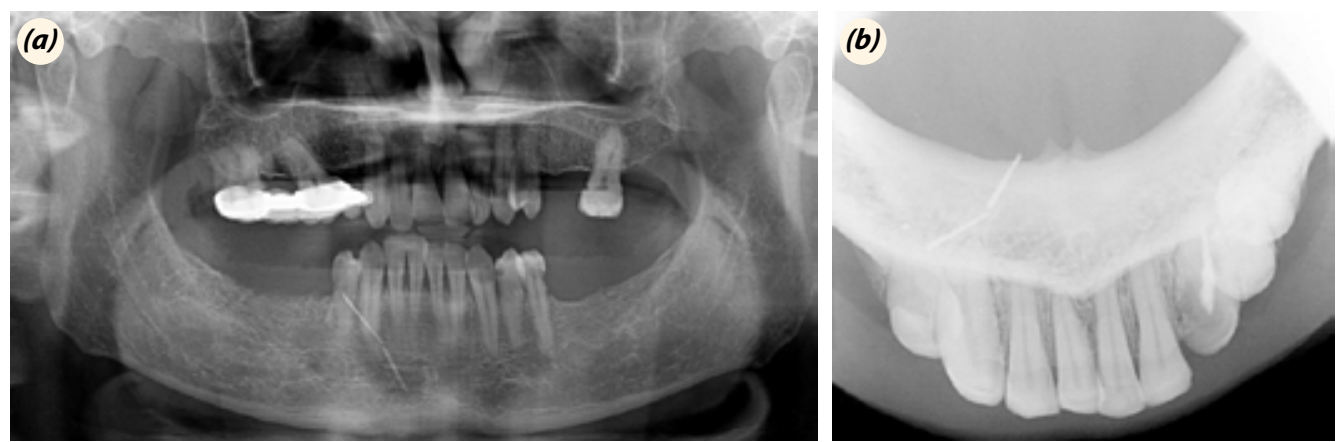

Fig. 1. (a) Gutta-percha points were seen in the right premolar lingual region using panoramic radiography. (b) Lingual localization of displaced gutta-perchas were seen in occlusal radiography.

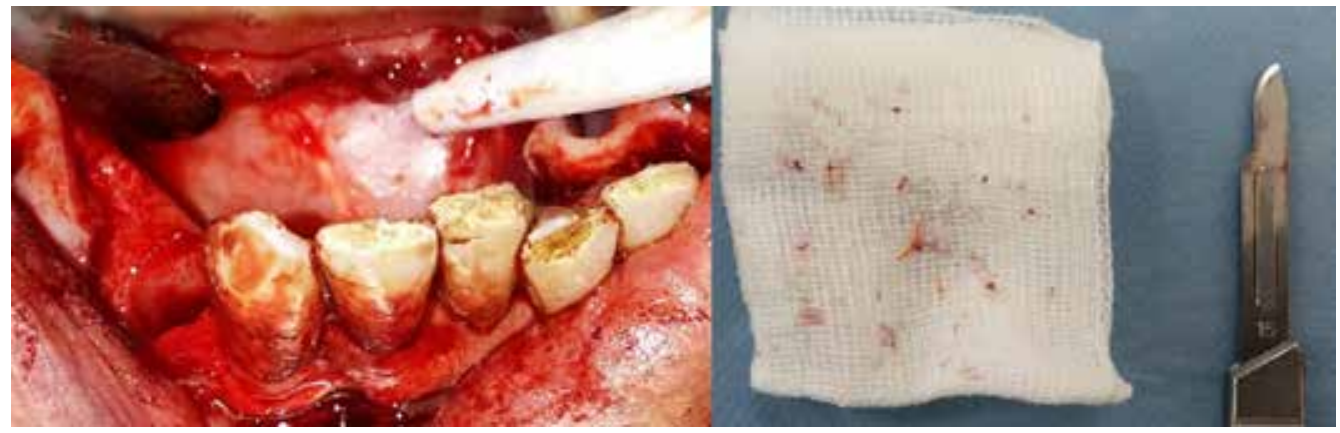

Fig. 2. Gutta-perchas and parts of removed gutta-perchas were seen in the lingual periosteum intraorally.

ment was applied to only second premolar tooth at the right mandibular region. The patient had heart failure and arrhythmia and was thus using an oral antiplatelet agent. According to the patient's medical history, the patient complained of foreign bodies and had a severe toothache in tooth 44, which had started a week earlier. Amoxicillin/clavulanate and an analgesic were given to the patient for five days. Endodontic treatment was recommended to patient but he refused. So on the fifth day, the first premolar was extracted, and the foreign bodies were removed surgically.

Because of the difficulty of localizing the gutta-perchas, occlusal radiography was used to determine their location (Figure lb). Two gutta-perchas were observed in the lingual premolar region. Bucco-lingual localization of gutta-perchas could be determined with occlusal radiography so there was no need to CT. Under local anesthesia, the causative tooth of the toothache was extracted and the bony region of this area was explored, but no guttapercha or other foreign material was found, so we decided to raise a full-thickness lingual flap. When the lingual flap was elevated, gutta-perchas were seen between the periosteum and the lingual submucosa. The bodies of the guttaperchas with the circumambient granulation tissue were extracted. It was quite difficult to reach the lower part of the gutta-perchas, which extended to the mandible, so a full-thickness flap was elevated to expose the genial tu- bercle and genioglossus muscle attachments. Thus, two gutta-percha points were removed piece by piece (Figure 2 ). Then, the flap was primary sutured, and the healing process, which was uneventful, was observed via postoperative radiography (Figure 3 ).

Overfilling of gutta-percha is a common complication of root canal treatment, but accidental displacement of gutta-percha to the lingual periosteum is an unusual complication. This case report shows that displaced guttapercha may cause an inflammatory reaction and pain. In this instance, suitable localization followed by surgical removal of extruded, displaced gutta-percha is an effective treatment approach for symptomatic relief and a satisfactory long-term outcome.

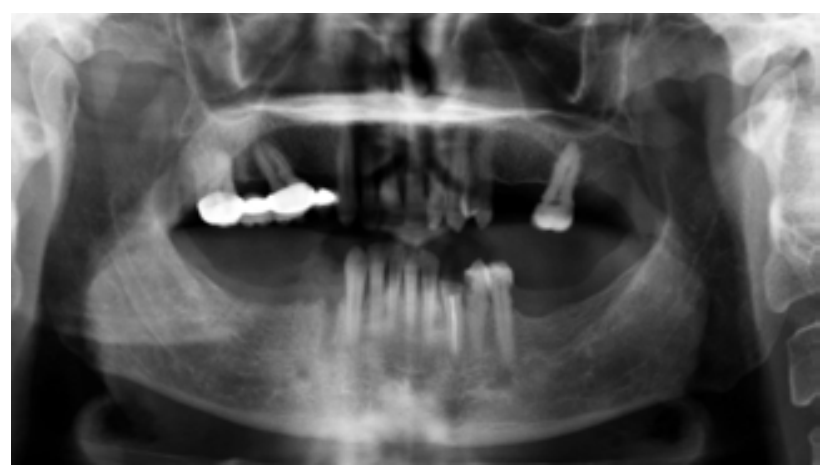

Fig. 3. Postoperative healing was seen in radiography. 


\section{Discussion}

There are risks in every endodontic procedure, and iatrogenic complications are usually a result of over-instrumentation of root canals in endodontic treatment. ${ }^{[6,7]}$ One of the most frequent complications of root canal treatment is overfilling, which adversely affects the outcome of root canal treatment. In the literature, overfilling is seen most commonly in the lower first and second premolars. ${ }^{[6,7]}$ In our case, during root canal treatment, the accidentally displaced gutta-perchas were seen in the lower second premolar region.

Gutta-percha is the most commonly used root canal filling material, typically used in combination with a sealer. ${ }^{[8]}$ It has been utilized as a chemical polyisoprene (crystalline polymer) in dentistry for over a century. ${ }^{[5]}$ Guttapercha has less toxicity compared with other components used in endodontic obstruction. Despite this low degree of toxicity, overfilling and/or overextended gutta-percha cause foreign body reactions. ${ }^{[5]}$

Wolfson and Seltzer injected gutta-percha in facial sides of the dorsal subcutaneous tissue of rats. ${ }^{[9]}$ Histologically, the implanted gutta-percha had an initial acute inflammatory effect within 15 days. Accordingly, the authors concluded that gutta-percha was "nontoxic" and "harmless." ${ }^{[9]}$ Many previously animal studies highlighted that gutta-percha is the least toxic and suitable material for connective tissue. ${ }^{[4]}$ In our case report, two gutta-perchas were accidentally displaced to the lingual periosteum, causing pain but resulting in no pathology around the lingual area.

Many clinical observations have shown that gutta-percha, sealers, or both cause clinical symptoms when overfilled and/or overextruded. For instance, the displacement of an extruded gutta-percha point from a root canal to the ethmoid sinus has been previously reported. ${ }^{[10]}$ The sinusitis symptoms were eliminated with surgical removal of the gutta-percha from the ethmoid sinuses. Our case also shows the displacement of two gutta-percha points from a root canal to the lingual periosteum. In the absence of clinical symptoms, gutta-percha can be followed-up, but if clinical symptoms result from displaced gutta-percha points, they should be removed surgically.

Gutta-percha that extrudes beyond the root canal system may cause an inflammatory reaction and pain. ${ }^{[4]}$ Even though more than half of overfilled teeth heal satisfactorily after proper endodontic therapy, in some cases, such as injury of the inferior alveolar nerve or the presence of filling material in soft tissues or sinus spaces, surgery is the most accepted intervention. ${ }^{[1]}$ In our case report, the patient had pain due to displaced gutta-perchas in the man- dibular premolar region. Thus, we decided to remove the displaced gutta-percha points from the lingual periosteum with surgical intervention.

\section{Conclusion}

The most important feature of this case report is to present accidental displacement of two gutta-perchas to lingual periosteum which is a rare endodontic treatment complication and it has never seen before in the literature. Based on this case report, clinicians should keep in mind that overfilled or overextruded gutta-percha could be displaced or migrate into the adjacent soft tissue (periosteum, etc.) or bone and cause symptoms, and this situation must be evaluated radiologically.

\section{Acknowledgement}

I affirm that I/We have no financial affiliation (e.g., employment, direct payment, stock holdings, retainers, consultantships, patent licensing arrangements or honoraria), or involvement with any commercial organization with direct financial interest in the subject or materials discussed in this manuscript, nor have any such arrangements existed in the past three years. Any other potential conflict of interest is disclosed."

\section{Conflict of interest: None declared.}

\section{References}

1. Brkić A, Gürkan-Köseoğlu B, Olgac V. Surgical approach to iatrogenic complications of endodontic therapy: a report of 2 cases. Oral Surg Oral Med Oral Pathol Oral Radiol Endod 2009;107:50-3, Crossref

2. González-Martín M, Torres-Lagares D, Gutiérrez-Pérez JL, Segura-Egea JJ. Inferior alveolar nerve paresthesia after overfilling of endodontic sealer into the mandibular canal. J Endod 2010;36:1419-21. Crossref

3. Poveda R, Bagán JV, Fernández JM, Sanchis JM. Mental nerve paresthesia associated with endodontic paste within the mandibular canal: report of a case. Oral Surg Oral Med Oral Pathol Oral Radiol Endod 2006;102:46-9. Crossref

4. Ektefaie MR, David HT, Poh CF. Surgical resolution of chronic tissue irritation caused by extruded endodontic filling material. J Can Dent Assoc 2005;71:487-90.

5. Gluskin AH. Mishaps and serious complications in endodontic obturation. Endodontic Topics 2005;12:52-70.

6. Pogrel MA. Damage to the inferior alveolar nerve as the result of root canal therapy. J Am Dent Assoc 2007;138:659. Crossref

7. Yamaguchi K, Matsunaga T, Hayashi Y. Gross extrusion of endodontic obturation materials into the maxillary sinus: a case report. Oral Surg Oral Med Oral Pathol Oral Radiol 
Endod 2007;104:131-4. Crossref

8. Fardal O, Johannessen AC, Morken T. Gingivo-mucosal and cutaneous reactions to amalgam fillings. J Clin Periodontol 2005;32:430-3. Crossref

9. Wolfson EM, Seltzer S. Reaction of rat connective tissue to some gutta-percha formulations. J Endod 1975;1:395-402. 10. Ishikawa M, Mizuno T, Yamazaki Y, Satoh T, Notani K, Fukuda $\mathrm{H}$. Migration of gutta-percha point from a root canal into the ethmoid sinus. Br J Oral Maxillofac Surg 2004;42:58-60. Crosstef 